\title{
Effect of Home Base Glucose Monitoring \& Self Dose Adjustment of Insulin on Glycosylated Hemoglobin
}

\author{
Maulik Shah ${ }^{1}$, Triya Malde ${ }^{2}$, Falgun Gondalia ${ }^{3}$, Sonal Shah ${ }^{4}$ \\ ${ }^{1}$ Associate professor, Department of paediatrics, M. P. Shah medical college, Jamnagar, India, ${ }^{2}$ Assistant professor, Department of paediatrics, M. P. Shah medical \\ college, Jamnagar, India, ${ }^{3}{ }^{\text {nd }}$ year resident, Department of paediatrics, M. P. Shah medical college, Jamnagar, India, ${ }^{4}$ Associate professor, Department of Paediatrics, M. P. \\ Shah medical college, Jamnagar, India
}

\section{Abstract}

Background: Type 1 Diabetes Mellitus (T1DM) is the most common endocrine metabolic disorder of childhood casing significant mortality and morbidity in childhood. Home Monitoring of Blood Glucose (HMBG) and Supplements of insulin as required depending on the blood glucose level at that time is a very important aspect of management in T1DM. The Goal of this study was to determine whether frequent checking of home base blood glucose (HMBG) levels accompanied with insulin self dose adjustment, will lead to improved metabolic control as assessed by reduction in the Glycosylated hemoglobin values (HbA1c). Subject and Method: This study was conducted in G.G.Hospital, M.P.Shah Medical college,Jamanagar between October 2012 to September 2013 for a period of 1 year including OPD and ward patients. Retrospective analysis of clinical profile of 37patients with T1DM attending our OPD between the age group of 2 to 16 years.A detailed clinical and family history, educational level of parents and insulin regime and insulin dose was recorded. Result: Age distribution in our study showed that $62 \%$ cases in the age of more than 10 years, $32 \%$ cases in the age group 5-10years and $2 \%$ cases falling in the age group $0-2$ years, with male to female ratio of a $1: 1.7$. The most frequently seen symptoms were polyuria (53\%), breathlessness (48\%),polydipsia (46\%), vomiting (29\%) of cases and $82 \%$ of the patients were ketotic at the time of presentation. In family members most common associated comorbidity is type $2 \operatorname{DM}(21 \%)$, hypertension $(21 \%) \&$ thyroid dysfunction (19\%). split regimen was observed in (70\%)and basal bolus regime in $(30 \%)$. split mix regime $11(42 \%)$ had $\operatorname{good}(<7 \mathrm{GHb})$ wheaeas Basal bolus regime $6(54 \%)$ of them had good control $\mathrm{p}=0.0308(<0.05)$. Conclusion: Regular Home monitoring of Blood glucose(HMBG) along with education on diabetes self management and regular contact with a member of a medical team for insulin dose adjustments with advice on meal planning and physical activity improve the metabolic control (as assessed by HbA1c levels) in children with T1DM.

Keywords: Diabetes Mellitus, education, insulin, thyroid dysfunction.

Corresponding Author: Dr. Triya Malde, Assistant professor, Department of paediatrics, M. P. Shah medical college, Jamnagar, India. Email: drpiyushpujara@gmail.com

Received: January 2020

Accepted: January 2020

\section{Introduction}

Type1 Diabetes Mellitus (T1DM) is the most common endocrine metabolic disorder of childhood and its incidence is gradually increasing in recent times. ${ }^{[1]}$ Good metabolic control is very important in these patients, which is achieved by, home Monitoring of Blood Glucose (HMBG) and Insulin therapy. ${ }^{[2]} \mathrm{HMBG}$ forms a very important aspect of management in T1DM.[3] Home Monitoring of Blood Glucose helps to:

a. Establish a glucose profile from day to day.

b. Make day-to-day decisions for managing blood glucose.

c. Confirm emergency situations such as hypoglycemia.

d. Prevent DKA on "sick days" by early intervention.

e. Study influence of food and activity on the blood glucose and correlation between 'How I feel' and 'My Blood Glucose'. [1]
On the bases of blood glucose levels, Supplements of insulin and adjustment of the insulin doses based on pattern recognition to be done. ${ }^{[1]}$

Due to low or absent levels of endogenously produced insulin in T1DM, insulin therapy forms the basis of its treatment. Insulin preparations commonly used include, Ultra short acting analogs (Aspart and Lispro), short acting regular insulin, Intermediate acting NPH insulin and long acting insulin analogs (Glargine and Detemir, which can be administered by various devices such as syringes, pens or insulin pumps which provide continuous subcutaneous insulin infusion (CSII). ${ }^{[4,5]}$ Various insulin regimes commonly used are the split-mix regime, the basal bolus regime and the insulin pump. ${ }^{[5]}$ Laboratory monitoring includes assessment of Glycosylated Hemoglobin (HbA1c). The hemoglobin A1c test reflects average level of blood sugar over the past 2 to 3 months.Reference range: Below 6-normal, 6-7:good control,7-8:fair, 8-10: unsatisfactory, $>10$ : poor. ${ }^{[1]}$

So presentstudy was aimed to see whether frequent checking 


\section{Shah et al; Glycasylated Hemaglalin}

of home base blood glucose (HMBG) levels accompanied with insulin self dose adjustment, will lead to improved metabolic control as assessed by reduction in the Glycosylated hemoglobin values (HbA1c) and to know influence of type of insulin regime on Glycosylated $\mathrm{Hb}$.

\section{Subjects and Methods}

This study was conducted in G.G.Hospital,, M.P.Shah Medical college, Jamanagar between October 2012 to September 2013 for a period of 1 year including OPD and ward patients. The total number of 37 Children and adolescents with T1DM between the age group of 2 to 16 years were included. This is retrospective study with randomized sample size of 37 with prior informed consent of parents of our children of our study.A detailed clinical and family history, educational level of parents and insulin regime and insulin dose was recorded.

Institutional Ethical committee for research on human subjects approved my study and clearance was given to the study protocol. Written informed consent of parent or guardian and assent (for those $>12$ years) was obtained for participation in the study prior to evaluation of their child.

\section{Inclusion criteria}

- Children and adolescents with T1DM attending our OPD between the age group of 2 to 16 years without specification for sex, religion or region were chosen.

- At our center, diagnosis of T1DM is based on the clinical presentation as this does not usually present any difficulty those who presented with persistant hyperglycemia with or without ketoacidosis associated symptoms like polyphagia, polyuria, polydipsia may or may not be present.

\section{Exclusion Criteria}

The study did not include

- Patients below the age of 2 years or above 16 years.

- Those who were not willing to comply with the regular blood glucose monitoring and regular contact for insulin dose modification were excluded.

- Newly diagnosed patients still in their honeymoon phase were not included.

\section{Selection of patients}

Enlisting of patients with T1DM randomly attending our OPD \& IPD at tertiary referral

centre hospital with government medical college Pediatric department.

\section{Intervention}

All the members of the study group and their parents were required to answer

Proforma.

Following information was elicited - Basic information,Probable etiological factors, Family history of autoimmunity. The patients and their parents were provided intensive education at

the outset to cover the following aspects of diabetes self management: They were then

motivated to check blood glucoselevels daily and to maintain a record. Home blood glucose

monitoring to be done with a glucometer. The meter provided free from juvenile diabetic

socitey.The patients were called to the clinic at 3 months. During the clinical visit following

information was derived -

Data on short term metabolic control: Episodes of hypoglycemia requiring assistance,

episodes of severe hypoglycemia with seizures or unconsciousness. Symptoms suggestive of

high blood glucose such as polyuria, nocturia and enuresis.

School absenteeism attributable to

diabetes.

Clinical examination: This included the height, weight, puberty status, blood pressure,

lipodystrophic changes, presence of hepatomegaly, limited joint mobility, neurological

examination in the form of deep tendon reflexes and superficial sensations.

Clinic visits were kept to a minimum and more stress was laid on telephonic contact so as to

drastically cut down on the money and time spent on travel. At the same time we could

maintain a constant contact with the patient and offer guidance as and when required.

\section{Outcome}

The study intends to ascertain whether frequent HMBG and guidance on necessary

intervention made possible by regular contact with a member of a medical team will help

improve the metabolic control in children with T1DM. Metabolic control was measured

objectively by HbA1c levels besides clinical criteria as listed above. HbA1c was measured at

start of study and again at the conclusion of study.

All patients were tested for their HbA1c values prior to entering the study. Test was repeated after constant contact with a member of a medical team after 3 months. Other specified investigations were done during the study period. The various investigations were done at a certified laboratory.

\section{Statistical analysis}

The recorded data was compiled and entered in a spreadsheet computer program (Microsoft Excel 2007) and then exported to data editor page of SPSS version 15 (SPSS Inc., Chicago, Illinois, USA). Descriptive statistics included computation of percentages, means and standard deviations. For all tests, confidence level and level of significance were set at $95 \%$ and $5 \%$ respectively. 


\section{Shah et al; Glycasylated Hemaglabin}

\section{Results}

Results were expressed as percentages and ratios. Out of 100 neonates, $70 \%$ were males and $30 \%$ were females.

Table 1: Age and Sex Distribution
\begin{tabular}{|l|l|l|l|}
\hline Age in years & Male & Female & Total \\
\hline$<5$ & $01(2.70 \%)$ & $01(2.70 \%)$ & $02(5.40 \%)$ \\
\hline $5-10$ & $2(5.40 \%)$ & $10(27.0 \%)$ & $12(32.40 \%)$ \\
\hline$>10$ & $11(29.73 \%)$ & $14(37.83 \%)$ & $23(62.16 \%)$ \\
\hline Total & $14(37.83 \%)$ & $25(67.56 \%)$ & $37(100 \%)$ \\
\hline
\end{tabular}

At present age and sex distribution of patients who developed diabetes between 5-10 years of age shows male are affected slightly higher rate than females.

\begin{tabular}{|l|l|}
\hline Table 2: presenting symptoms at time of diagnosis \\
\hline Presenting symptom & No. of patients \\
\hline weakness & 10 \\
\hline Vomiting & 18 \\
\hline Breathlessness & 19 \\
\hline Polyuria & 21 \\
\hline Polydipsia & 18 \\
\hline Polyphagia & 11 \\
\hline Fever & 3 \\
\hline
\end{tabular}

Maximum number of patients having presenting symptoms due to hyperglycemia like vomiting, polyuria, polyphagia, breathlessness, weakness, weight loss and symptoms due to ketosis like breathlessness All the patients having more than one clinical presentation.Out of 37 patients, $32(86.4 \%)$ patients had ketosis on first admission at the time of diagnosis.

Table 3: Family History of Associated Comorbidities (degree of relative affected)

\begin{tabular}{|l|l|l|l|}
\hline Family History of & \multirow{2}{*}{$\begin{array}{l}\text { No. of } \\
\text { Associated } \\
\text { comorbidities }\end{array}$} & Patients & Degree of relation \\
\cline { 3 - 4 } & & First & Second \\
\hline Type 1DM & $6(16.2 \%)$ & 2 & 4 \\
\hline Type 2DM & $8(21.6 \%)$ & 1 & 7 \\
\hline Thyroid & $6(18.7 \%)$ & 2 & 4 \\
\hline Hypertension & $8(21.6 \%)$ & 4 & 4 \\
\hline Alopecia & $4(10.8 \%)$ & 1 & 3 \\
\hline vitiligo & $4(10.8 \%)$ & 1 & 3 \\
\hline $\begin{array}{l}\text { No family memember } \\
\text { affected }\end{array}$ & $10(27 \%)$ & \multicolumn{2}{|l}{} \\
\hline Total & $37(100 \%)$ & & \multicolumn{2}{|l}{} \\
\hline
\end{tabular}

In family members most common associated co-morbidity is type 2 DM, hypertension \& thyroid dysfunction. Co morbidities commonly seen in second degree $(69 \%)$ relatives followed by first degree relatives $(31 \%)$.

Table 4: Types of Insulin Regimen used by Patients

\begin{tabular}{|l|l|l|}
\hline Insulin Regimen & No. of Patients & Percentage \\
\hline Mixed Split & 26 & $70.0 \%$ \\
\hline Basal Bolus & 11 & $30.0 \%$ \\
\hline Total & 37 & $100 \%$ \\
\hline
\end{tabular}

As seen above majority of patients taking mixed split
Table 5: Influence of regime on G-Hb

\begin{tabular}{|c|c|c|c|c|}
\hline \multirow[t]{2}{*}{ G-Hb } & \multicolumn{2}{|c|}{ Type of regime } & \multirow[t]{2}{*}{ Total } & \multirow{2}{*}{$\begin{array}{l}\mathbf{P} \\
\text { Value }\end{array}$} \\
\hline & $\begin{array}{l}\text { Split } \\
\text { mix }\end{array}$ & $\begin{array}{l}\text { Basal } \\
\text { bolus }\end{array}$ & & \\
\hline Good-Fair $(<8)$ & 14 & 10 & $24(65 \%)$ & \multirow{3}{*}{$0,04 *$} \\
\hline Poor- & 12 & 1 & $13(35 \%)$ & \\
\hline Unsatisfactory $(>8)$ & $26(70 \%)$ & $11(30 \%)$ & $37(100 \%)$ & \\
\hline
\end{tabular}

Test applied chi0square test, $*$ indicates statistically significance at $\mathrm{p} \leq 0.05$

Association between G-hb and Type of regime was significant statistically $(\mathrm{p} \leq 0.05)$ (Table 5)

Table 6: Thyroid Autoimmunity among the patients

\begin{tabular}{|l|l|l|l|l|}
\hline \multirow{2}{*}{ Age } & \multicolumn{2}{|l|}{ Thyroid disorder } & \multirow{2}{*}{ Total } & \multirow{2}{*}{ P value } \\
\cline { 2 - 4 } & Present & Absent & & \\
\hline$>10$ years & 1 & 13 & 14 & \multirow{2}{*}{0.5} \\
\hline$<10$ years & 5 & 18 & 23 & \\
\cline { 2 - 4 } & $6(16 \%)$ & $31(84 \%)$ & $37(100 \%)$ & \\
\hline
\end{tabular}

Test applied chi0square test, statistically significance at $\mathrm{p} \leq 0.05$

Non-significant association was observed between thyroid disorder and Age ( $>>0.05)$

Low birth weight was present in $13 \%$ of patients. Maximum number of patients had birth weight between 2.5 to 3.0 kg.Out of 37 patients, 24(64.8\%) patients had taken exclusive breastfeeding for 6 months and more. 13 patients had taken exclusive breast-feed less then six months.

Table 7: Influence of self dose adjustment on G-Hb

\begin{tabular}{|l|l|l|l|l|}
\hline \multirow{2}{*}{ G-Hb } & \multicolumn{2}{c|}{$\begin{array}{c}\text { Self dose } \\
\text { adjustment }\end{array}$} & \multirow{2}{*}{ Total } & $\begin{array}{l}\text { P } \\
\text { value }\end{array}$ \\
\cline { 2 - 4 } & Yes & No & & \\
\hline Good-Fair( $<8)$ & 24 & 3 & 27 & \multirow{2}{*}{$0.002^{*}$} \\
\hline $\begin{array}{l}\text { Poor- } \\
\text { Unsatisfactory( }>8)\end{array}$ & 2 & 8 & 10 & \\
\cline { 2 - 3 } & $26(67.5 \%)$ & $11(32.5 \%)$ & $37(100 \%)$ & \\
\hline
\end{tabular}

There was significant association was observe between metabolic control and Self dose adjustment. $(p \leq 0.05)$ (Table 7) there was also statistical significant association between Meal planning \& councelling session attended and metabolic control. $(\mathrm{p} \leq 0.05)$.

Table 8: Effect of HMBG on hospitalization

\begin{tabular}{|l|l|l|l|l|}
\hline \multirow{3}{*}{ Hospitalization } & \multicolumn{2}{|c|}{ SMBG per } & Total & $\begin{array}{l}\text { P } \\
\text { vay }\end{array}$ \\
\cline { 2 - 4 } & $\mathbf{2}$ times & $\mathbf{< 2 ~ t i m e s}$ & & \\
\hline Once or less & 12 & 5 & 17 & 0.1 \\
\hline Twice or more & 16 & 4 & 20 & \\
\cline { 2 - 4 } & $28(76 \%)$ & $9(24 \%)$ & $37(100 \%)$ & \\
\hline
\end{tabular}

Test applied chi0square test, statistically significance at $\mathrm{p} \leq 0.05$

Non-significant association was observed between SMBG per day and Hospitalization $(\mathrm{p}>0.05)($ Table 8$)$

\section{Discussion}

The presentation of new-onset T1D is distributed among three typical patterns: classic new onset, silent diabetes, and 


\section{Shah et al; Glycasylated Hemaglabin}

diabetic ketoacidosis (DKA). Although, most children present with classic new-onset diabetes, in many locations, DKA still accounts for $20 \%$ to $40 \%$ of all new diagnoses. ${ }^{[6]}$ Children who have silent (i.e., diagnosed early in the course of) T1DM are typically diagnosed by families or physicians with a high index of suspicion.

In our study, the sex distribution showed a slight predominance of females with $67.5 \%$ and $37.8 \%$ males. At the time of study, $5.4 \%$ of patients are below five years of age, $32.4 \%$ of patients between $5-10$ years of age, $62.1 \%$ of patients above 10 years of age. In the study by Formosa N, et $a l^{[42]}$, the highest annual increase in incidence of type-1 DM occurred in the 0-4 year age group at 39\% per year, closely followed by 5-9 years age group at 31\% per year.

Out of 37 patients, presented with symptoms of hyperglycemia in the form of polyuria 57\%, polyphagia $28 \%$, polydipsia $49 \%$, weakness $27 \%$. Those who presented late came with additional symptoms that suggested the presence of ketoacidosis, these symptoms were in the form of breathlessness in 52\%, and vomiting $48 \%$.

Out of 37 patients $86 \%$ presented with ketoacidosis on first admission. Al-Rashed $\mathrm{AM}^{7}$ studied 369 diabetic children, most $(n=321)$ children had polyuria $87 \%$ as the presenting symptom; other symptoms included - polydipsia $84 \%$, weight loss $83.9 \%$, nocturia $65 \%$, diabetic ketoacidosis (DKA) $47.20 \%$ and abdominal pain $46.6 \%$.

This indicates lack of awareness among parents and medical persons for diagnosis of type $1 \mathrm{DM}$ to catch in early symptomatic phase hence most of them present in ketoacidosis also young children cannot effectively express the subjective symptoms leading to possibility of delay in receiving appropriate treatment.

$27 \%$ had no family history suggestive of autoimmunity. Type 2 DM (21\%) and hypertension (21\%), Hypothyroidism (18\%) seen to be the most common of associated co morbidities. Malcova H, et al (2004) ${ }^{[8]}$ found an increased prevalence of autoimmunity especially T1DM and thyroid dysfunction in first degree relatives of patients with T1DM was $14.5 \%$.

$70 \%$ of patients were using the split mix regime while the remaining $30 \%$ patients were on the basal-bolus regime. None of the patient on insulin pump.Basal bolus regime is more physiological method of giving insulin and should be routinely used from the outset in patients who can afford the additional cost and are also motivated not only to make multiple shots but also perform frequent $\mathrm{HMBG}$ and act on the results.

In our study 26 patients were on split mix regime out of them $11(42 \%)$ had $\operatorname{good}(<7 \mathrm{GHb})$ control,3(11\%) had fair(7$8 \mathrm{GHb})$ control and $6(11 \%)$ had unsatisfactory $(8-10 \mathrm{GHb}) \&$ poor $(>10 \mathrm{GHb})$ control each.11 patients were on Basal bolus regime $6(54 \%)$ of them had good control,4(36\%) had fair and only $1(9 \%)$ had unsatisfactory control.

Chi square test was applied to know statistical association of type of regime used on metabolic control. $\mathrm{p}=0.0308(<0.05)$ which is significant. Thus Basal bolus regime has better metabolic control in our study that can be explained as it more physiological compares to split mix regime.

Rosenstock J et al,(2005) ${ }^{[\mathbf{9}]}$ reported that patients with glargin insulin had improved metabolic control $\mathrm{G}-\mathrm{Hb}<7$ in compare to those who were on mixtard insulin. $\mathrm{P}=0.0442(<0.05)$ In our study, $42 \%$ of patients who were on split mix regime never had hypoglycemia on the contrary to basal bolus $36 \%$ of them had no hypoglycemia. $63 \%$ of basal bolus users had $\geq 1$ episodes of hypoglycemia in contrast to $57 \%$ of the split mix users.

Chi-square test applied to know statistical association between Insulin regime used and episodes of hypoglycemia. $\mathrm{p}=0.7364(>0.05)$ hence there is no statistical association between type of insulin regime and hypoglycemic episodes. Rosenstock J et al,(2005) ${ }^{[9]}$ Also reported glargin users have reduced hypoglycemia compare to mixtard.

$6(16.2 \%)$ out of 37 patients had thyroid dysfunction and 5 patients $(13.5 \%)$ had antithyroid antibody positive out of this all five patients had high TSH were started on thyroid replacement therapy while the remaining patients required only close follow-up as they may develop hypothyroidism later in life. Franzese A, et al $(2000)^{[10]}$ reported an incidence of $18.1 \%$ with female : male ratio of $2: 1$. Darendeliler FF, et al (1994) ${ }^{[11]}$ reported a prevalence of thyroid autoimmunity in T1DM patients to be $18.8 \%$.We found that five of them were adolescent female. Lorini $\mathrm{R}$, et al $(1996)^{[12]}$ have noted a significantly higher prevalence in females.

In our study $13 \%$ patients had low birth weight. Low birth weight may be associated with a higher risk of metabolic syndrome in later life. ${ }^{[13]}$ The low BMI at birth and the later increase in the following years of life seem to be related to intrauterine environment as a risk factor for T1DM.

$45 \%$ were breastfed for less than 6 months, 55\% were breastfed for more than 6 months. Studies conducted by Sadauskaite-Kuehne V, et $\mathrm{al}^{[14]}$ and Gimeno SG, et $\mathrm{al}^{[15]}$ have shown that breastfeeding for longer duration is associated with a low risk of developing T1DM. Although, some studies have not shown such an association. ${ }^{16}$ Whether prolonged breast feeding per se protects against Type-1 diabetes or whether the delayed introduction of cow milk in breast fed babies reduces the risk of developing diabetes is not certain.

In our study those who were doing self dose adjustment (25 children,68\% of study group) out of them 17 had excellent blood sugar control ,7 had good sugar control, 2 had fair control ,only 1 had poor sugar control based on Glycosylated $\mathrm{Hb}$. Thus $88 \%$ of children who were doing self dose adjustment had good sugar control. Chi square test applied to know association between self dose adjustment and $\mathrm{G}-\mathrm{Hb}<8$ good/fair \&>8 unsatisfactory/poor .p value $0.0002(<0.05)$ which is significant. Alemzadeh R, Wyatt $\mathrm{DT}^{17}$ Have shown that self dose adjustment in insulin therapy under medical person guidance significant $(\mathrm{p}=0.0014)$ improvement on metabolic control base on Glycosylated $\mathrm{Hb}$. 


\section{Shah et al; Glycasylated Hemaglalin}

In our study out of 37 total $26(70 \%)$ had attended meal planning \& counseling sessions out of them $61 \%$ had good metabolic control(G-Hb <7), $23 \%$ had fair control(G-Hb 7$8), 11 \%$ had unsatisfactory ( $\mathrm{G}-\mathrm{Hb} 8-10), 3 \%$ had poor $(\mathrm{G}-\mathrm{Hb}$ $>10$ ) and Remaining 11 patients those who had not attended counseling sessions $30 \%$ had unsatisfactory (G-Hb 8-10) and $38 \%$ had poor $(\mathrm{G}-\mathrm{Hb}>10)$ control. Chi square was applied to know statistical association between Glycosylated $\mathrm{Hb}$ and meal planning and counseling session attended or not. p value was 0.0005 which is $<0.05$ hence significant association found. DAFNE study group et al.2012 ${ }^{18}$ skilled training promoting dietary freedom with self dose adjustment improves quality of life and glycemic control without worsening hypoglycemia.

In our study the patients who were doing HMBG 3 times or more per day out of them $70 \%$ had good metabolic control ( $\mathrm{G}-\mathrm{Hb}<7), 30 \%$ of them had fair control (G-Hb 7-8) none of them had poor or unsatisfactory control. On the contrary those who were doing $\mathrm{HMBG}$ only once or no $\mathrm{HMBG}$ at home $56 \%$ of them had poor control(G-Hb $>10), 40 \%$ had unsatisfactory control (G-Hb 8-10).To know statistical association between HMBG and Glycosylated $\mathrm{Hb}$ Chisquare test was applied $\mathrm{p}$ value was $0.0074(<0.05)$ which is significant. Hence HMBG can improve metabolic control. Svein skeie et $\mathrm{al}^{[6]}$ Self-Monitoring of Blood Glucose in Type 1 Diabetes Patients with Insufficient Metabolic Control: Focused Self-Monitoring of Blood Glucose Intervention Can Lower Glycosylated Hemoglobin A1C.(78\% of study group had improved metabolic control ,p value $=0.001)$.

In our study 11 patients were doing $\mathrm{HMBG} \geq 3$ times a day out of them $73 \%$ had only single admission in last one year and $9 \%$ had three or more admission. 17 patients were doing HMBG twice a day out of them only $29 \%$ had three or more admission whereas 9 patients were doing HMBG once or none per day out of them $33 \%$ had three or more hospital admission in last year. To know statistical association between HMBG and Hospitalization Chi-square test was applied p value was 0.7791(>0.05) which is NOT significant. Hence HMBG has no statistically significant association with hospitalization.

\section{Conclusion}

Regular Home monitoring of Blood glucose(HMBG) along with education on diabetes self management and regular contact with a member of a medical team for insulin dose adjustments with advice on meal planning and physical activity improve the metabolic control (as assessed by HbA1c levels) in children with T1DM. Frequent HMBG helps detect asymptomatic hypoglycemia and treat it promptly. With simple meal planning and counseling sessions one can have frequent HMBG with self dose adjustment of insulin which ultimately improves metabolic control. But such education forms a very important part of day-to-day diabetes management. Basal bolus regime (Glargin) has good metabolic control compare to split mix regime. Some common associated co morbidities like hypothyroidism $16.2 \%$ in our study was there hence should be screened at time of diagnosis only hence can be managed at early stage.

\section{References}

1. Nelson Textbook Of Pediatrics $19^{\mathrm{TH}}$ Edition Kliegman,Stanton,St.Geme,Behrman \&The Eurodiab Tiger Study Group : recent trends in the incidence of Type 1 diabetes in European children. Diabetologia. 1998; 41(1) : A21.

2. Aronson R, Abitbol A, Tweden KS. First assessment of the performance of an implantable continuous glucose monitoring system through 180 days in a primarily adolescent population with type 1 diabetes. Diabetes Obes Metab. 2019 Jul;21(7):1689-1694.

3. Christiansen MP, Klaff LJ, Bailey TS, et al. A prospective multicenter evaluation of the accuracy and safety of an implanted continuous glucose sensor: the PRECISION study. Diabetes Technol Ther. 2019 May;21(5):231-237.

4. Mehra NK, Kumar N, Kaur G, Kanga U, Tandon N. Biomarkers of susceptibility to type 1 diabetes with special reference to the Indian population. Indian J Med Res. 2007; 125 : 321-344.

5. Knip M, Veijola R, Virtanen SM, Hyoty H, Vaarala O, Åkerblom1 HK. Environmental Triggers and Determinants of Type 1 Diabetes. Diabetes. 2005;54(Suppl. 2) : S125-S136.

6. Svein skeie et al. Journal of Diabetes Sci Technol. 2009 January; 3(1): 83-88. Nyomba BLG, Berard L, Murphy LJ. The Cost of SelfMonitoring of Blood Glucose Is an Important Factor Limiting Glycemic Control in Diabetic Patients. Diabetes Care.2002; 25 : 1244-1245.

7. Al-Rashed AM. Pattern of presentation in type 1 diabetic patient. Ann Saudi Med. 2011 May-Jun; 31(3) : 243-249.

8. 8. Giuliana Valerio, Maria Immacolata Spagnuolo, Francesca Lombardi, Raffaella Spadaro, Maria Siano, Adriana Franzese. Physical activity and sports participation in children and adolescents with type 1 diabetes mellitus. Nutr Metab Cardiovasc Dis. 2007 Jun ; 17(5) : 376-382.

9. Rosenstock J. Meta-analytical comparison between diabetic patients using glargin and mixtard insulin for reduction of hypoglycemia and reduction in Glycosylated hemoglobin. Diabetes care.2005;April,28(4)950-5.

10. Franzese A, Buono P, Mascolo M, Leo AL, Valerio G. Thyroid autoimmunity starting during the course of type 1 diabetes denotes a subgroup of children with more severe diabetes. Diabetes Care. 2000; 23 : 1201-1202.

11. Darendeliler FF, Kadioğlu A, Bas F, Bundak R, Günöz H, Saka N, Neyzi OR. Thyroid ultrasound in IDDM. J Paediatr Endocrinol. 1994 Jan-Mar; 7(1) : 33-37.

12. Lorini R, D'Annunzio G, Vitali L and Scaramuzza A. IDDM and autoimmune thyroid disease in the pediatric age group. J Paediatr Endocrinol and Metabol. 1996; 9(1) : 89-94.

13. Garcia Cuartero. The low BMI at birth and the later increase in the following years of life seem to be related to intrauterine environment as a risk factor for T1DM. 2009 Jun;70(6):542-6.

14. Sadauskaite-Kuehne V, Ludvigsson J, Padaiga Z, Jasinskiene E, Samuelsson U. Longer breastfeeding is an independent protective factor against development of type 1 diabetes mellitus in childhood. Diabetes Metab Res Rev. 2004 Mar-Apr; 20(2) : 150-157.

15. Gimeno SG, de Souza JM. IDDM and milk consumption. A casecontrol study in São Paulo, Brazil. Diabetes Care. 1997 Aug; 20(8) : 1256-1260.

16. Meloni T, Marinaro AM, Mannazzu MC, Ogana A, La Vecchia C, Negri E, Colombo C. IDDM and early infant feeding. Sardinian case-control study. Diabetes Care. 1997 Mar; 20(3) : 340-342.

17. Alemzadeh R, Wyatt DT. Diabetes Mellitus in children, In : Nelson's textbook of pediatrics, 17th edition (2004). Saunders Publishers, pp 1947-1971.

18. DAFNE study group et al.2012 .BMJ Oct 2012;325;746-9. 
Copyright: (C) the author(s), 2020. It is an open-access article distributed under the terms of the Creative Commons Attribution License (CC BY 4.0), which permits authors to retain ownership of the copyright for their content, and allow anyone to download, reuse, reprint, modify, distribute and/or copy the content as long as the original authors and source are cited.

How to cite this article: Shah M, Malde T, Gondalia F, Shah S. Effect of Home Base Glucose Monitoring \& Self Dose Adjustment of Insulin on Glycosylated Hemoglobin. Asian J. Clin. Pediatr. Neonatol.2020;8(1):15-20.

DOI: dx.doi.org/10.47009/ajcpn.2020.8.1.4

Source of Support: Nil, Conflict of Interest: None declared. 